\title{
A Lithosphere-Atmosphere-Ionosphere Coupling Phenomenon Observed Before M 7.7 Jamaica Earthquake
}

\author{
Muhammad Arqim Adil, ${ }^{1}$ (D) Erman Şentürk, ${ }^{2}$ Sergey Alexander Pulinets, ${ }^{3}$ and Christine Amory-Mazaudier ${ }^{4,5}$
}

\begin{abstract}
The satellite-based earth observations have become an appropriate instrumental approach in monitoring the natural hazards among modern-day researchers. This study presents a multi-parameter approach using precursors of different physical nature defining the states of atmosphere and the ionosphere in terms of temporal and spatial variations about 5 days before the impending M 7.7 Jamaican earthquake (EQ). We performed a comprehensive analysis from the surface to the ionosphere at different altitude levels by analyzing the different datasets comprising, surface air temperature, relative humidity, total column water vapor, air pressure, Outgoing Longwave Radiations (OLR), and the total electron content of the global ionosphere maps (GIMTEC). We observed a sharp increment in the atmospheric chemical potential (ACP) due to the increased radon activity that led to an abrupt decrement in the atmospheric relative humidity and, consequently, increased OLR that provides strong evidence of the air ionization production around the epicenter of M 7.7 EQ. Moreover, to check the periodicity of these atmospheric parameters, we performed a confutation analysis by meticulously analyzing these parameters in the same month and region for the previous 5 years during the non-existence of any major seismicity. This technique confirmed that the simultaneous atmospheric variations observed before the Jamaica EQ are not cyclic in the absence of significant seismic activities. The ionospheric conditions have also shown consistency with atmospheric disturbances, as depletions in GIMTECs, having an amplitude of 4 TECU, are observed over the epicenter for $6 \mathrm{~h}(\mathrm{LT}=13-19$ (- UT)) on January 23, 2020. Additionally, the vertical ionospheric and atmospheric profiles from FORMOSAT-7/COSMIC-2 (F7/C2), at different altitudes (75-225 km) over the EQ epicenter, showed significant depletions on January 23, 2020. These TEC variations are observed to be an effect of the vertical seismogenic electric field due to the
\end{abstract}

1 Department of GNSS, Institute of Space Technology, Islamabad 44000, Pakistan. E-mail: arqamadil3@gmail.com

2 Department of Geomatics Engineering, Kocaeli University, 41001 Kocaeli, Turkey.

3 Space Research Institute, Russian Academy of Sciences, Moscow 117997, Russia.

4 Sorbonne Université, Ecole polytechnique, Institut Polytechnique de Paris, Université Paris Saclay, Observatoire de Paris, CNRS, Laboratoire de Physique des Plasmas (LPP), 75005 Paris, France.

5 T/ICT4D, ICTP, International Centre for Theoretical Physics, Strada Costiera, 11, 34151 Trieste, Italy. production of the air ionization at the atmospheric boundary layer by increased radon activity around the seismic preparation zone. The existence of these co-located synchronized atmospheric and ionospheric anomalies is explicitly and persistently local over a small region of the epicenter of Jamaican EQ that could be considered as potential short-term precursors. Also, these multiobserved anomalies will contribute to the physical explanation of the Lithosphere-Atmosphere-Ionosphere Coupling (LAIC) model.

Keywords: LAIC model, earthquake precursors, atmospheric and ionospheric interaction, FORMOSAT-7/COSMIC-2, 2020 Jamaica EQ M 7.7.

\section{Introduction}

The earthquake (EQ) phenomenon has a great contribution to aggregation and sudden energy releases to the atmosphere and ionosphere. The scientists often suggested that the EQs are extremely difficult to predict or even cannot be predicted due to their complex nature (Toker, 2021). Geller (1997) draws a completely pessimistic picture describing the attempts of EQ prediction, however, Keilis-Borok (2003) sees the perspective of prediction technology improvements in the nearest future especially taking into account that "the prediction of complex systems requires a holistic approach "from the whole to details" in consecutive approximations starting with the most robust coarse-graining of the processes considered". His prophecy is confirmed by the recent advances in satellite-based observations that have provided extensive evidence in momentary anomalies proceeding EQs (Adil et al., 2021a, 2021b; De Santis et al., 2019; Hsiao et al., 2009; Oyama et al., 2011; Pulinets \& Ouzounov, 2018; Şentürk et al., 2019). The existence of pre-EQ seismically induced atmospheric precursors can be found in various studies 
(Blackett et al., 2011; Cervone et al., 2006; Mansouri Daneshvar et al., 2014; Ouzounov et al., 2007; Xiong et al., 2010). Similarly, many studies have widely reported the seismo-ionosphere anomalies (SIAs) as potential precursors to the EQs (Kamogawa, 2006; Liu et al., 2010; Pulinets \& Ouzounov, 2018; Su et al., 2013; Yan et al., 2018; Zhou et al., 2017). Furthermore, the SIAs have engaged great controversy over the years, as some scientists (Masci \& Thomas, 2014; Thomas et al., 2012) claimed that the SIAs reported by Pulinets et al. (2007) and Su et al. (2013) were largely contributed by global geomagnetic activity and they have no relationship to the seismic event. They also suggested that the physical mechanism behind the generation of these anomalies should be explained properly, as many researchers have directly related the ionospheric variations to some seismic events that cause ambiguity.

Some studies have explained the physical mechanisms behind the generation of these ionospheric anomalies (De Santis et al., 2015; Freund et al., 2009; Kamogawa, 2006). Pulinets and Ouzounov (2018) suggested that substantial radon tends to be released during tectonic plate motion where various gases such as carbon dioxide, helium, methane, and hydrogen serve as carriers disclosing it to the atmosphere. These radon emanations lead to air ionization, and with the condensation of water vapor, latent heat of vaporization is produced, which is responsible for atmospheric disturbances. The SIAs are the results of variation in the atmospheric electric field caused by the formation of ion clusters at the atmospheric boundary layer producing the local modification of the Global Electric circuit, which are reflected in the ionosphere as the large-scale ionospheric irregularities (Pulinets \& Davidenko, 2014). On the other hand, Kuo et al. (2014) proposed a LAIC model explaining the formation of the vertical electric field due to the production of positive charges over the Earth's surface. They suggested that this electric field elevates the vertical current flow to the upper atmosphere. The positive and negative ions present in the ionosphere are enforced to undergo upward-downward flows. This process initiates the movement of plasma bubbles which may be responsible for TEC variations. Here, one should keep in mind the limitations of the proposed mechanism of Kuo et al. (2014) because of the following facts: (1) the "positive holes" effect is a substantially solid body phenomenon, which cannot be generated and observed over the ocean areas regardless many EQs have their epicenters in oceans and pre-EQ ionospheric anomalies are equally observed over ocean EQs as over the land; (2) plasma bubbles are essentially equatorial ionosphere phenomena that do not develop in the middle and highlatitude ionosphere, where pre-EQ anomalies are observed as well.

Many studies have presented different multi-instrumental approaches in pursuit of physical and chemical changes that may arise before an EQ activity. Ouzounov et al. (2011) reported some morphological features, like variations in ionospheric TEC and atmospheric parameters about 5 days prior to the 2011 M 9.1 Tohoku-Oki EQ. Similarly, some strong collocated perturbations in ionospheric TEC and different atmospheric observables were observed about 2-3 months before the impending M 7.5 Indonesia $\mathrm{EQ}$, however, these anomalies were not obvious ones but possibly associated with this EQ (Marchetti et al., 2020). Also, some significant enhancements/depletions in multi-atmospheric parameters along with ionospheric variations were statistically detected as possible precursors about 25-30 days before 2010 Illapel EQ (Mansouri Daneshvar \& Freund, 2017). Despite all of these studies, there is still a lack of conclusiveness. We believe that the only way to study the range and impact of the seismically induced perturbations is to start analyzing from ground level.

Our approach is based on the understanding that the seismic preparation area is the center stage for the interaction of the different geophysical shells. The system of geophysical shells (lithosphere, neutral atmosphere, and ionosphere) can be analyzed as an open nonlinear system. Internal dissipation within the system together with correlated interaction of its elements, a process of self-organization can occur due to intensive exchange of matter and energy with the environment in non-equilibrium conditions. These processes accompanied by the synchronization of the geosphere's characteristics could lead the system to a critical state. The synchronization of the geosphere's characteristics can be spatial, temporal, or spatio-temporal. The main purpose of this paper is 
not only the demonstration of the multiparameter approach but to reveal the synchronization in time and space of different atmospheric and ionospheric parameters that testifies the approaching of the system to the critical point. As an example of our approach, we present the analysis of the seismically induced perturbations from ground level to the ionosphere as potential precursors to the recent 2020 M 7.7 Jamaica EQ. This EQ is reported as one of the largest ones occurring around the world in 2020 and the largest one in the Caribbean since 1946. The data and methodology adopted in this study are briefly described in Sect. 2. The results are given in Sect. 3 and discussed in Sect. 4. Finally, conclusions are provided in Sect. 5 .

\section{Data and Methods}

\subsection{Data Preparation}

In this study, the spatial and temporal variations in the lower atmospheric and the ionospheric parameters are analyzed over the epicenter of M 7.7 Jamaican EQ. Figure 1 shows the epicenter of M 7.7 Jamaica EQ along with the tectonic settings of its surrounding areas. This EQ $\left(19.419^{\circ} \mathrm{N} 78.756^{\circ} \mathrm{W}\right)$ was occurred on January 28, 2020, at 19:10 UT, having a depth shallower than $20 \mathrm{~km}$ in the northwest of the Lucea, Jamaica. The region of the EQ is controlled by the motion of the North America and Caribbean tectonic plates, where the North America plate moves towards the west-southwest to the Caribbean plate at a rate of approximately $19 \mathrm{~mm} /$ year. The rupture was leftlateral towards the east-northeast indicating a strikeslip fault mechanism. The fault plane extending approximately in the east-west direction is in line with the orientation of the regional plate boundary (U.S. Geological Survey, 2020).

To analyze the atmospheric composition during the seismic activity period, we analyzed the temporal variations of atmospheric relative humidity, surface air temperature (SAT), and total column water vapor for January 2020 through NASA's online database (https://gmao.gsfc.nasa.gov/). Furthermore, to check and validate the novelty of any variation in these datasets as a seismic influence, we constructed the confidence bounds based on the median (M) and interquartile range (IQR) for a period of 5 years in the same month January without any significant seismicity. For the construction of these bounds, the time series should be ordered in ascending $\left(\mathrm{x}_{1}, \mathrm{x}_{2}\right.$, $\mathrm{x}_{3} \ldots \mathrm{x}_{27}, \mathrm{x}_{28}$ ), where $\mathrm{x}$ values correspond to the daily data for a fixed epoch within 28 days. The lower quartile $\mathrm{Q}_{1}$, middle quartile $\mathrm{Q}_{2}$, upper quartile $\mathrm{Q}_{3}$, and interquartile range (IQR) are calculated to determine upper and lower bounds using Eqs. 1-4.

$$
Q_{1}=\frac{x_{7}+x_{8}}{2}
$$

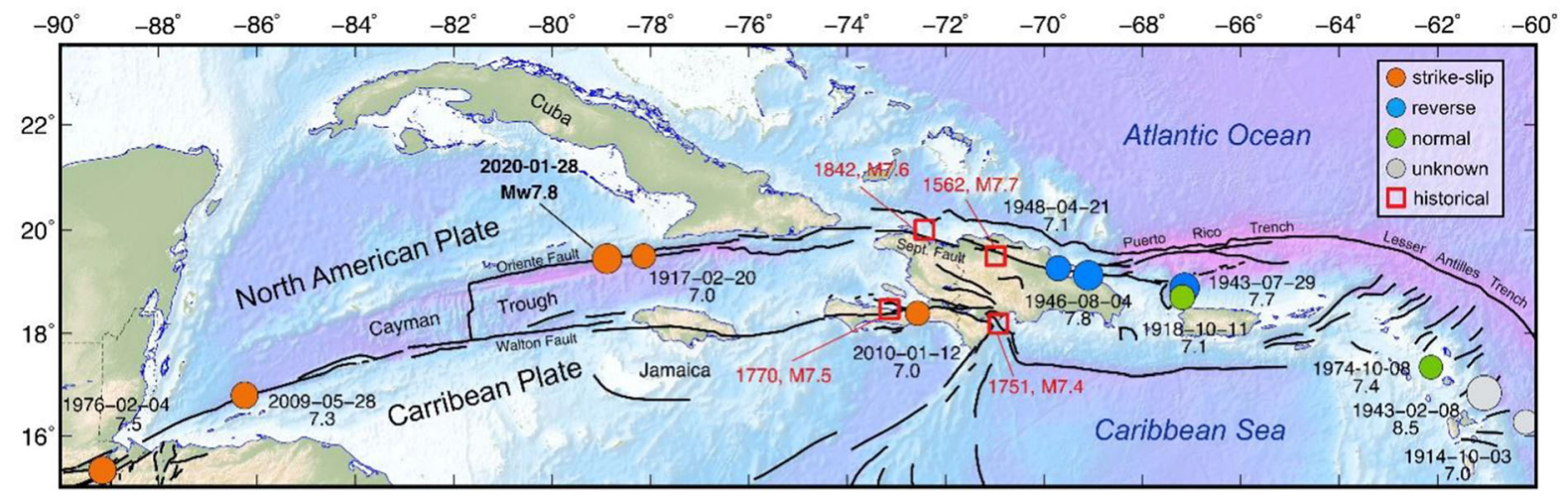

Figure 1

Spatial distribution of the strong $(M \geq 7)$ earthquakes (from http://www.geologie.ens.fr/ ecalais/_Media/map_large.jpeg) that occurred in the Caribbean basin. The focal mechanisms of the earthquakes are marked by color (see legend inside the figure). Black lines indicate the faults (http://www.geologie.ens.fr/ ecalais/research/the-january-28-mw78-cayman/) 


$$
\begin{gathered}
Q_{2}=M=\frac{x_{14}+x_{15}}{2} \\
Q_{3}=\frac{x_{21}+x_{22}}{2} \\
I Q R=Q_{3}-Q_{1}
\end{gathered}
$$

The lower (LB) and upper bounds (UB) for the outlier test are as follows (Varotsos et al., 2017):

$$
\begin{aligned}
& U B=M+2 I Q R \\
& L B=M-2 I Q R
\end{aligned}
$$

Equations 5-6 declared that, with a $99.63 \%$ confidence level, either observed values falling over these bounds will be declared as an abnormal value.

The spatial anomaly datasets of several variables, including SAT, relative humidity, air pressure, and outgoing longwave radiations (OLR) at different analysis levels, like, at the surface $(0 \mathrm{~km}$ from mean sea level), $7 \mathrm{~km}, 9 \mathrm{~km}$, and $12 \mathrm{~km}$ above mean sea level respectively, were retrieved from National Oceanic and Atmospheric Administration-Physical Sciences Laboratory (NOAA-PSL) via http://psl. noaa.gov/data/composites/day. We performed a subtraction method to eliminate the seasonality of the datasets, where the anomaly map of each observed day, was subtracted with the mean of the previous 5 days (Freeshah et al., 2021), as represented by Eq. 7:

$$
\mu_{r e s}=\mu_{o b s}-\frac{\sum_{k=1}^{n}\left(\mu_{k}\right)}{n}
$$

where $\mu_{o b s}$ is mean anomaly map for the observed day and $\mu_{\text {res }}$ is the resultant mean anomaly map of the desired parameter. According to Dobrovolsky et al. (1979), the area of the EQ preparation zone is defined by the formula given as $r=10^{0.43 M}$, where $\mathrm{M}$ represents the magnitude of the EQ and $r$ represents the radius of the preparation zone. According to this formula, the radius of the Jamaican EQ extends to $\sim 2046 \mathrm{~km}$, which covers an area of almost $0-36^{\circ}$ $\mathrm{N}$ in latitude and $58-98^{\circ} \mathrm{W}$ in longitudes. All the spatial and temporal datasets were retrieved, specifically, in the region of $\pm 10^{\circ}$ around the epicenter that falls within the EQ preparation zone.

Now, to explore the ionosphere conditions, we considered GIM-TEC maps with a spatial resolution of $2.5^{\circ}$ and $5.0^{\circ}$ (Latitude, Longitude) having a temporal resolution of $2 \mathrm{~h}$ from Jet Propulsion Laboratory (JPL) via ftp://gssc.esa.int/gnss/products/ ionex/. JPL GIMs are known to have an accuracy of approximately 4-5 TECU globally (Hernández-Pajares et al., 2009), and 2-3 TECU in the low latitude region and under low solar activity (Wielgosz et al., 2021). One may also use two convenient methods named auto-covariance estimation of variable samples (ACEVS) and differential areas for differential stations (DADS) to reveal ionospheric anomalies under stationary conditions (Yuan \& Ou, 2001, 2002). The TEC describes the total number of electrons in a cylinder with a one-meter square base area throughout the line of sight (LOS) connecting the satellite and the receiver. It is represented in TECU units, where one TECU is equal to $10^{16}$ electrons per meter square. Since the ionosphere is largely influenced by solar and geomagnetic activities (Afraimovich \& Astafyeva, 2008), therefore, the solar index F10.7 and the geomagnetic Kp and Symmetric-H (SYMH) indices are used to distinguish the global from the local effects.

\subsection{Calculation of F7/C2 vertical TEC profiles}

We utilized the atmospheric and ionospheric data of FORMOSAT-7/COSMIC-2 (F7/C2) to crosscheck and reinforce our results. The COSMIC-2 mission was launched on June 25, 2019, and planned as a continuation of the COSMIC-1, consisting of six satellites into low-inclination orbits for observing and monitoring the global meteorology, climate, and the ionosphere. The six satellites collect weather data between $\pm 50^{\circ}$ of the $\mathrm{N}-\mathrm{S}$ latitudes and provide more than 4000 atmospheric/ionospheric profiles each day (Schreiner et al., 2020). F7/C2 provides the ionospheric observations of radio occultation (RO) such as the electron density, relative TEC, and $\mathrm{S} 4$ index from $\sim 70 \mathrm{~km}$ in altitude to LEO orbit. We used the TEC data of two GNSS ROs, G07 and G28, which are located near the epicenter. Also, the ionospheric TEC maps over the epicenter were analyzed from 75 to $225 \mathrm{~km}$ on January 23 (anomaly day). These maps were constructed from TEC profiles of GNSS ROs that were located in the EQ preparation zone. The ionospheric data was obtained 
from the ionPrf files from https://data.cosmic.ucar. edu/gnss-ro/cosmic2/nrt/. The calibrated occultation TEC values in the GNSS RO technique are calculated from the calibrated phase $(\Delta \mathrm{L})$ using the following formula, where $f_{1}$ and $f_{2}$ are the carrier frequencies of L1 and L2 signals, respectively.

$$
T E C_{\text {calibrated }}=\frac{\Delta L_{\text {calibrated }}}{40.3 \times 10^{16}} \times \frac{f_{1}^{2} f_{2}^{2}}{f_{1}^{2}-f_{2}^{2}}
$$

We used the calibrated TEC for the reconstruction of the electron density profiles. Firstly, the electron density at the orbit altitude is determined by linear regression of the square of the calibrated TEC for the top few kilometers of the tangent point. TEC near orbital altitude is extracted by the following formula where $\mathrm{p}$ is the impact parameter, $\mathrm{N}_{\mathrm{e}}$ is the electron density, and $\mathrm{p}_{\max }$ is the maximum impact parameter which is approximately equal to the orbit radius.

$$
T E C(p) \approx 2 N_{e}\left(p_{\max }\right) \sqrt{2 p_{\max }\left(p_{\max }-p\right)}
$$

The calibrated TEC is spline interpolated to the regular grid of impact parameters on the occultation side, and it is inverted to an electron density profile using Eq. 10 (so-called onion peeling method) where $p_{i}$ is equal to $p_{\max }$ at the orbit altitude.

$$
N_{e}\left(p_{i}\right)=\frac{3}{4} \frac{T E C\left(p_{i}\right)}{\sqrt{2 p_{i}\left(p_{i+1}-p_{i}\right)}}-\sum_{k=1}^{n-i} c_{k, i} N_{e}\left(p_{i+k}\right)
$$

The coefficients, $c_{k, i}$ are derived in Syndergaard et al. (2005). F7/C2 vertical TEC profiles are calculated using the integration of the electron density profiles from $80 \mathrm{~km}$ to orbit altitude where negative values of electron density are not included.

The atmospheric profiles such as temperature, pressure, water vapor pressure, and vertical refractivity index can be obtained from the surface up to $60 \mathrm{~km}$ with a vertical resolution of $0.05 \mathrm{~km}$ using wetPf2 files (Ho et al., 2020). We investigated the air temperature and pressure data of F7/C2 from January 20 to January 28 with analysis levels at the surface and 300mb ( $\sim 9 \mathrm{~km})$, respectively. The data covers $10-30^{\circ} \mathrm{N}$ latitudes and $70-90^{\circ} \mathrm{W}$ longitudes.

\subsection{Exploration of LAI anomalies: approach}

It is indispensable to comprehend the associated processes and the geology around the EQ preparation zones to attain sturdy insight into the induction of seismic anomalies that further interact with the atmosphere. Radon emanations from rocks due to stress effect along fault lineaments had widely reported as a potential seismically induced gas (Giuliani et al., 2009; Hauksson, 1981; King, 1981; Richon et al., 2003; Woith, 2015). Moreover, the increased radon discharges from macroscopic faults (such as an EQ activity) have been proved experimentally (Mollo et al., 2011; Tuccimei et al., 2010). Pulinets et al. (2015) proposed a mechanism describing that the radiation ionization associated with radon gas initiates several chemical and physical processes in the atmosphere. The condensation of water vapor takes place due to the formation of large clusters of ions as a result of the chemical reaction and ionization process. This water vapor condensation is further responsible for the release of latent heat of vaporization at a large scale. These plasma-chemical compositions produced by increased radon emanations are responsible for variations in air temperature and relative humidity over a seismically active region (Dunajecka \& Pulinets, 2005; Ouzounov et al., 2018; Pulinets et al., 2015). Furthermore, Planinić et al. (2001) observed and reported an anticorrelation between radon and air pressure during the analysis of long-term data of 2 years between 1999 and 2000 before some EQs. They claimed that increasing radon was observed to cause significant depletion in air pressure before the analyzed EQs. Due to these atmospheric circulations, the latent heat releases that further generate some extra heat flux that could be enveloped in the form of OLR. OLR is the thermal radiation egress from the top of the atmosphere (10$12 \mathrm{~km}$ ) that establishes a connection with the earthatmosphere system and depends on the SAT (Ouzounov et al., 2007). Now further, the variating air humidity and the radioactive decay of radon releasing $\alpha$-particles are the main source of air ionization which further contributes to the formation of the ions of aerosol-size particles. Boyarchuk et al. (1998) performed some numerical calculations that resulted in changing the atmospheric electric field in the 


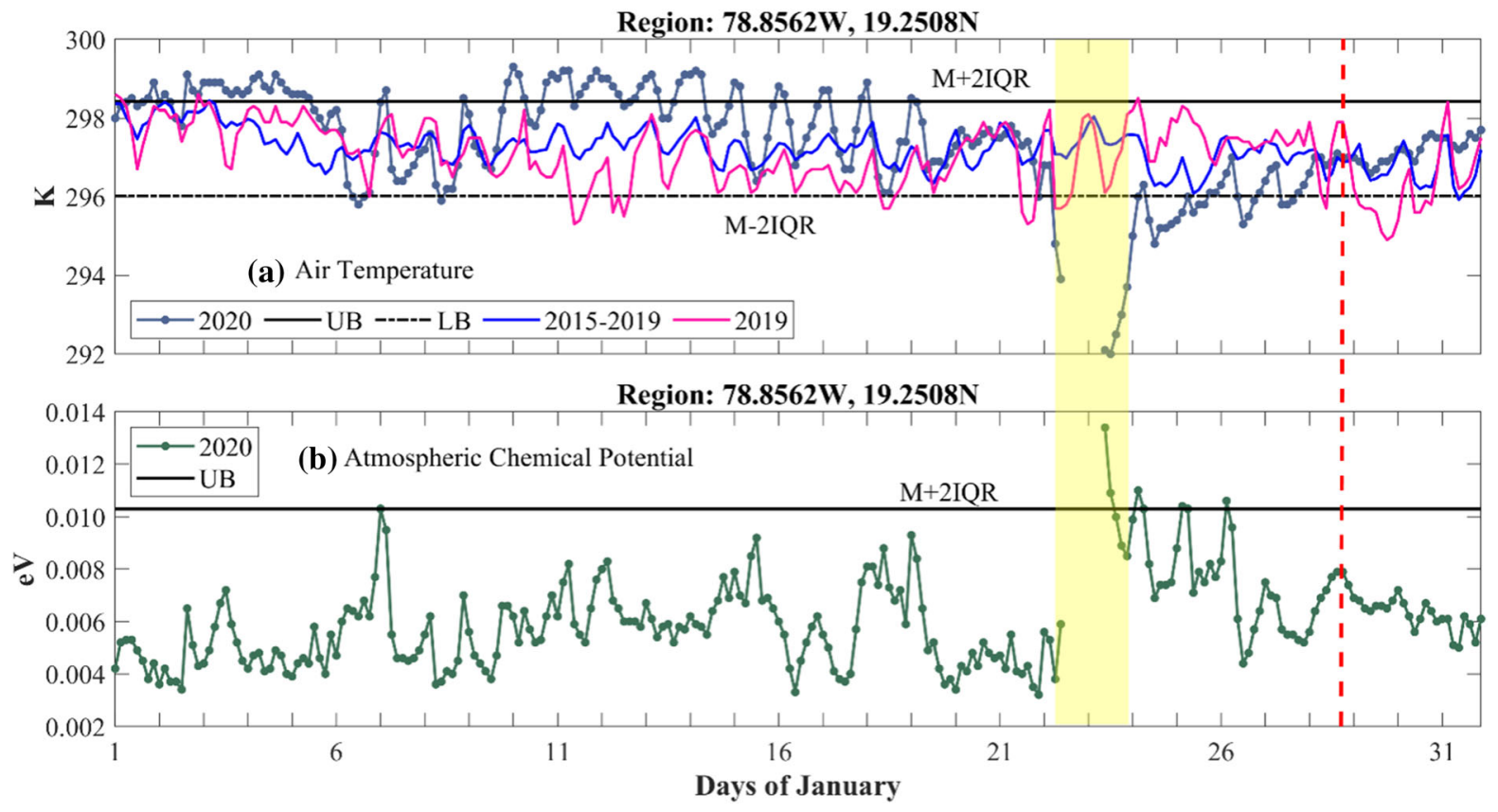

Figure 2

a The time series of SAT over the epicentral region, where the solid-dotted dark blue line represents the SAT values for January 2020 . The solid blue line represents the SAT mean values for the 5-years between 2015 and 2019. Similarly, the pink solid line indicates the SAT time series for January 2019 as a confutation analysis. The solid and dashed-dotted black lines denote the corresponding UB and LB, respectively. b the temporal variations of the ACP datasets for the month of January 2020, where a solid black line represents the corresponding UB. The dashed red line represents EQ day. The yellow area represents anomalous activities well exceeding the corresponding UB and LB

presence of the aerosols flux. The variating atmospheric boundary layer conductivity having anomalous atmospheric electricity is mainly responsible for the ionospheric irregularities. The physical interpretation of this phenomenon was further carried out by Kuo et al. (2014) that explained the ionospheric perturbations influenced by this electric field.

Besides, previous studies were very limited to the investigation of a couple of parameters or sometimes to an individual parameter without using multi parameters to show any correlation within different layers of the geosphere. In this study, we will not only demonstrate the multiparameter investigation but also reveal the synchronization in time and space of different atmospheric and ionospheric parameters that testifies the approaching of the system to the critical point. In addition, we are undertaking longterm temporal datasets to investigate the novelty of the results by expanding the analysis to those without significant seismicity periods to confirm the nonexistence of such anomalies. Due to the lack of data availability, we were unable to accumulate the direct radon measurements around M 7.7 Jamaican EQ. However, as the increased radon flings along the macroscopic fault lineaments have proved experimentally by Mollo et al. (2011), we have considered all those parameters that are directly or indirectly related to increased radon emissivity and may play an important part in EQ forecasting. On the other hand, during the air ionization process produced from increased radon activity, the latent heat of vaporization is equal to its chemical potential at phase transition (Pulinets et al., 2015). According to Boyarchuk et al. (2006), for a given relative humidity $(H)$ and SAT $\left(T_{g}\right)$, the correction of the chemical potential of the atmosphere can be calculated as:

$$
\Delta U=5.8 \times 10^{-10}\left(20 T_{g}+5463\right)^{2} \ln (100 / H)
$$

We estimated the atmosphere chemical potential (ACP) with temporal datasets of the atmospheric relative humidity and SAT for January 2020 using the 


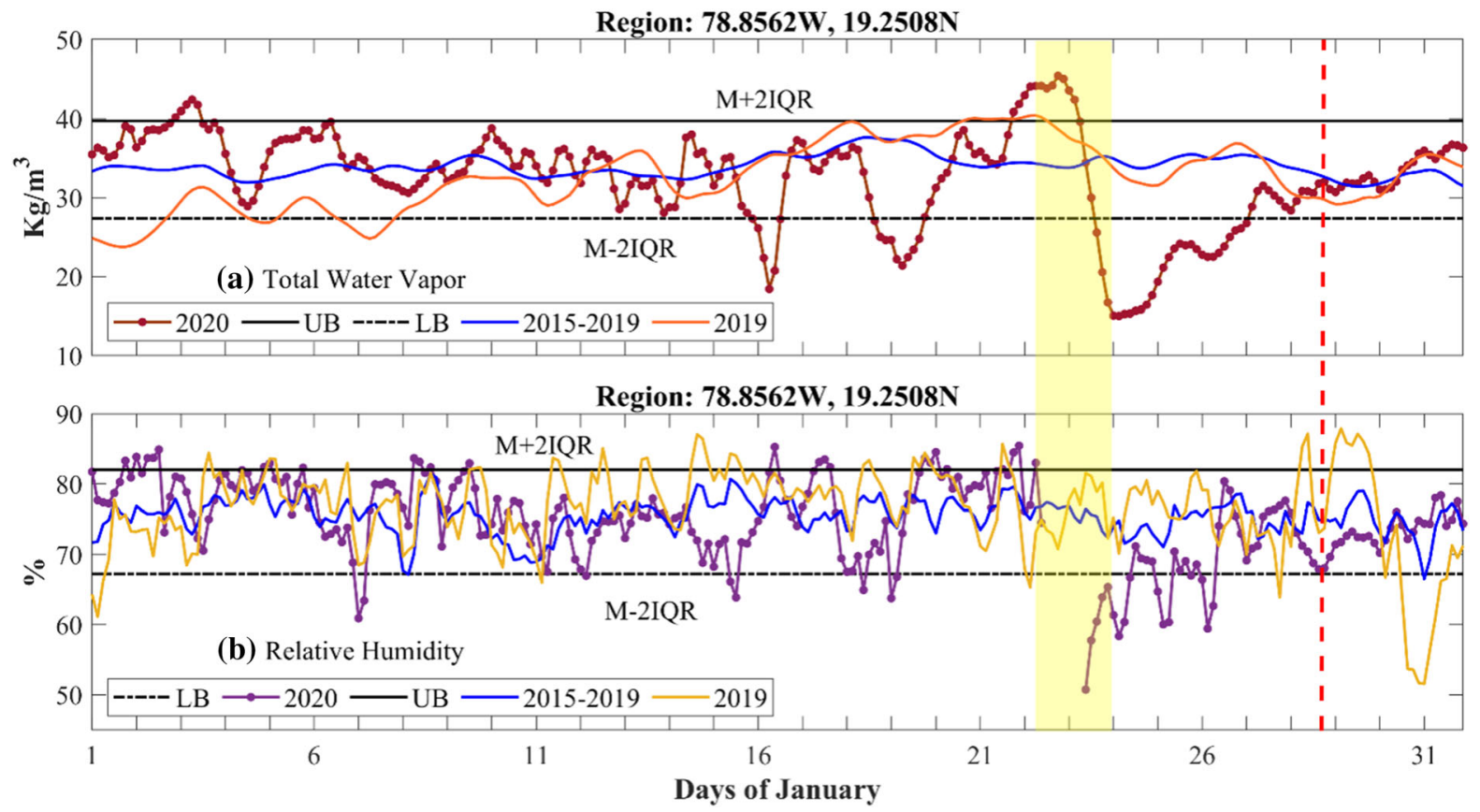

Figure 3

a The time series of total column water vapors over the epicentral region, where the solid-dotted dark brown line represents the water vapor values for January 2020. The solid blue line represents the water vapor mean values for the 5-years between 2015 and 2019 . Similarly, the red solid line indicates the water vapor time series for January 2019 as a confutation analysis. b The relative humidity temporal variations, where solid-dotted purple and solid yellow lines represent its variations for years 2020 and 2019, respectively. The solid blue line represents the water vapor mean values for the 5-years between 2015 and 2019. The solid and dashed-dotted black lines denote the corresponding UB and LB, respectively, in both panels. The dashed red line represents EQ day. The yellow area represents anomalous activities well exceeding the corresponding UB and LB

Eq. 11, which can be interpreted as the increased radon activity.

\section{Results}

Radon during its decay emits energetic $\alpha$-particles with the energy $E_{\alpha}=5.46 \mathrm{MeV}$. Since the energy of atmospheric gas ionization lies within the range of 10-30 eV, each $\alpha$-particle can produce on average $\sim 3 \times 10^{5}$ electron-ion pairs (Pulinets et al., 2015). After the series of plasma chemical reactions, the primary ions form the positive and negative terminals which start to be hydrated by the attachment to the water molecules present in the atmospheric air. During every act of water molecule attachment, it emits at least the thermal energy of $0.433 \mathrm{eV}$ called the latent heat of condensation. By this process, the free water vapor is removed from the atmosphere resulting in the humidity drop, and latent heat release leads to an increase in the air temperature. The latent heat of vaporization is equal to the ACP during its phase transition. In this sense, the ACP can be regarded as the increased radon activity. Figure 2 represents the temporal variations of the ACP data for the month of January 2020. One can observe that the ACP abruptly increase to attain a value of $0.014 \mathrm{eV}$ on January 23, 2020 (Fig. 2b), which suggests an increased radon activity around the epicenter of the M 7.7 EQ.

In comparison to normal circumstances, the increased radon coalescence yields a drop in relative humidity and consequently alters air temperature (Pulinets et al., 2015). From Fig. 3, one can see the temporal dynamics of the relative humidity on the epicenter of the Jamaica earthquake where during one and half days, from 21:00 UT on 21 January to 09:00 UT of 23 January, the relative humidity dropped 

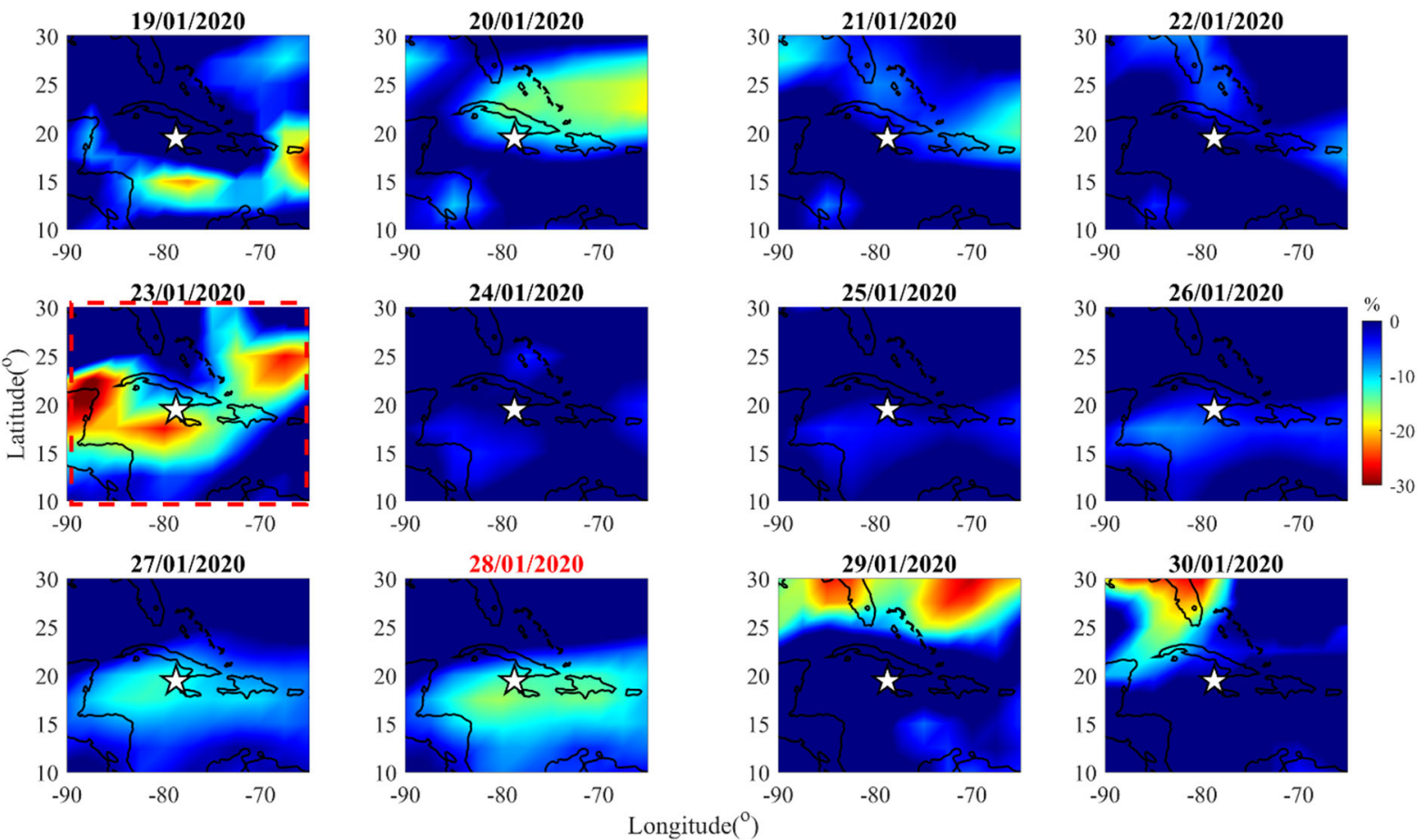

Figure 4

Short-term Spatio-temporal anomaly maps of mid-tropospheric relative humidity from NOAA, at an altitude of $7 \mathrm{~km}$ above mean sea level, between January 19 and 30, 2020. The epicenter of M 7.7 EQ is represented by a white star. The dashed-red square exhibits the anomalous day

to $\sim 50 \%$ from $\sim 85 \%$. Similarly, Fig. 4 describes the spatial distribution of the mid-tropospheric relative humidity where it significantly dropped to $\sim 25 \%$ on January 23 , compared to the other days ( 5 days before the EQ), over and around the epicenter of M 7.7 Jamaica EQ. On the other hand, we observed a peculiar phenomenon in the SAT time series where the SAT values have sharply decreased to more than $4 \mathrm{~K}$ from the corresponding $\mathrm{LB}$ on January 23, 2020 (Fig. 2a). The spatial anomaly maps of the SAT suggest a similar drop of $4 \mathrm{~K}$ explicitly over the epicenter, compared to the rest of the analyzed days (Fig. 5). This decrease of the air temperature simultaneously with the growth of the ACP is observed to be a very rare effect (Fig. 2). It could be explained in the following way: probably the sharp drop of relative humidity led to the drop of the air pressure according to Dalton's law of partial pressures because of the drop of the water vapor partial pressure. On days 22-23 January, the cold was approaching from the northwest direction, and a sharp depression over the impending EQ's epicenter sucked down the tongue of the cold air in the preparation area of the M 7.7 Jamaica EQ, which led to the temperature drop.

Such a drop in relative humidity (Fig. 3a) and increased ACP (Fig. 2b), resulting in the condensation of water vapor and latent heat release before the EQs, are the main drivers of the air ionization. In general, latent heat increases due to an increase in evaporation, which is a result of an increased amount of water vapor around the EQ epicenter (Mansouri Daneshvar et al., 2014). Figure 3a represents the time series for the total column water vapor during the whole month of January 2020. We observed a significant increase in column water vapor of about $\sim 4 \mathrm{~kg} / \mathrm{m}^{3}$ from the corresponding UB on January 23, 2020. It is worth noting that $\sim 2494 \mathrm{~J}$ of heat releases during condensation of only $1 \mathrm{~g}$ of water vapor from each cubic meter of air that further results in about a $6.7 \%$ drop of relative humidity, which has been confirmed by satellite-based 

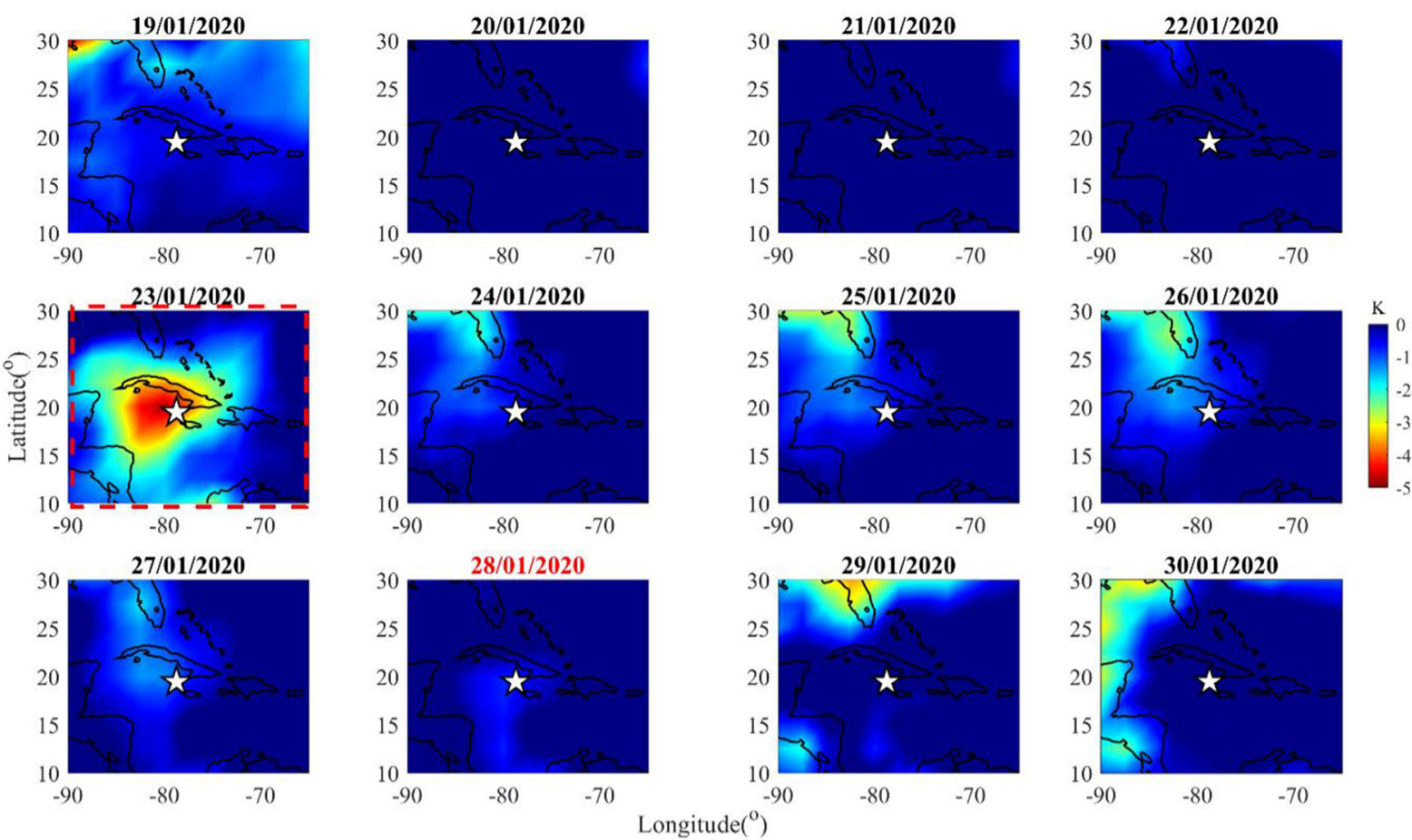

Figure 5

Spatial anomaly maps of surface air temperature from NOAA between January 19 and 30, 2020, where white star represents the epicenter of Jamaica EQ. The dashed-red square exhibits anomalous days

measurements (Pulinets \& Ouzounov, 2018). Additionally, radon emitted $\alpha$-particles carry average energy of about $6 \mathrm{MeV}$ and can generate up to $4.5 \times$ $10^{5}$ ions-electron pair. In an experimental study conducted by Wilding and Harrison (2005), it was observed that a single ion may carry a hundred water molecules. Hence, the increased amount of water vapor will provide a large number of water molecules to radon ions, and as a consequence, an increase in latent heat. Another atmospheric phenomenon related to the increased radon is the atmospheric pressure. Figure 6 delineates a peculiar decrease of 14 millibars $(\mathrm{mb})$ in air pressure on January 23, 2020 (5 days before the EQ), which is another sign of increased radon activity over the $\mathrm{M}$ 7.7 EQ preparation zone. On the other hand, the radon-induced ionization exists at different levels in the atmosphere, the combined energy released by each $\alpha$-particle will be finally converted to heat at the top of the atmosphere, which can be monitored by the satellite in the form of OLR. Figure 7 represents an enormous increase of about $30 \mathrm{~W} / \mathrm{m}^{2}$ in the OLR values on January 23, 2020, right over and around the epicenter of M 7.7 Jamaica EQ, which provides another indication of the seismically induced atmospheric environment.

Furthermore, the air ionization, produced by increased radon emanations and column water vapor, is the main source of ions production at the atmospheric Planetary Boundary Layer (PBL). The air ionization further provides increased air conductivity at PBL by formulating large ion clusters having a size of aerosols size particles that lead to a generation of the steady steep electric field over the entire EQ preparation area, which is responsible for ionospheric variabilities (Pulinets \& Davidenko, 2014). Hence, in order to testify to an agreement with atmospheric variations observed on January 23, 2020, we used bihourly GIM-TEC maps for that particular day to study the ionospheric effects engendered by gigantic M 7.7 Jamaican tremblor. Figure 8 represents spatial GIM-TEC anomaly maps on January 23, 2020, where 

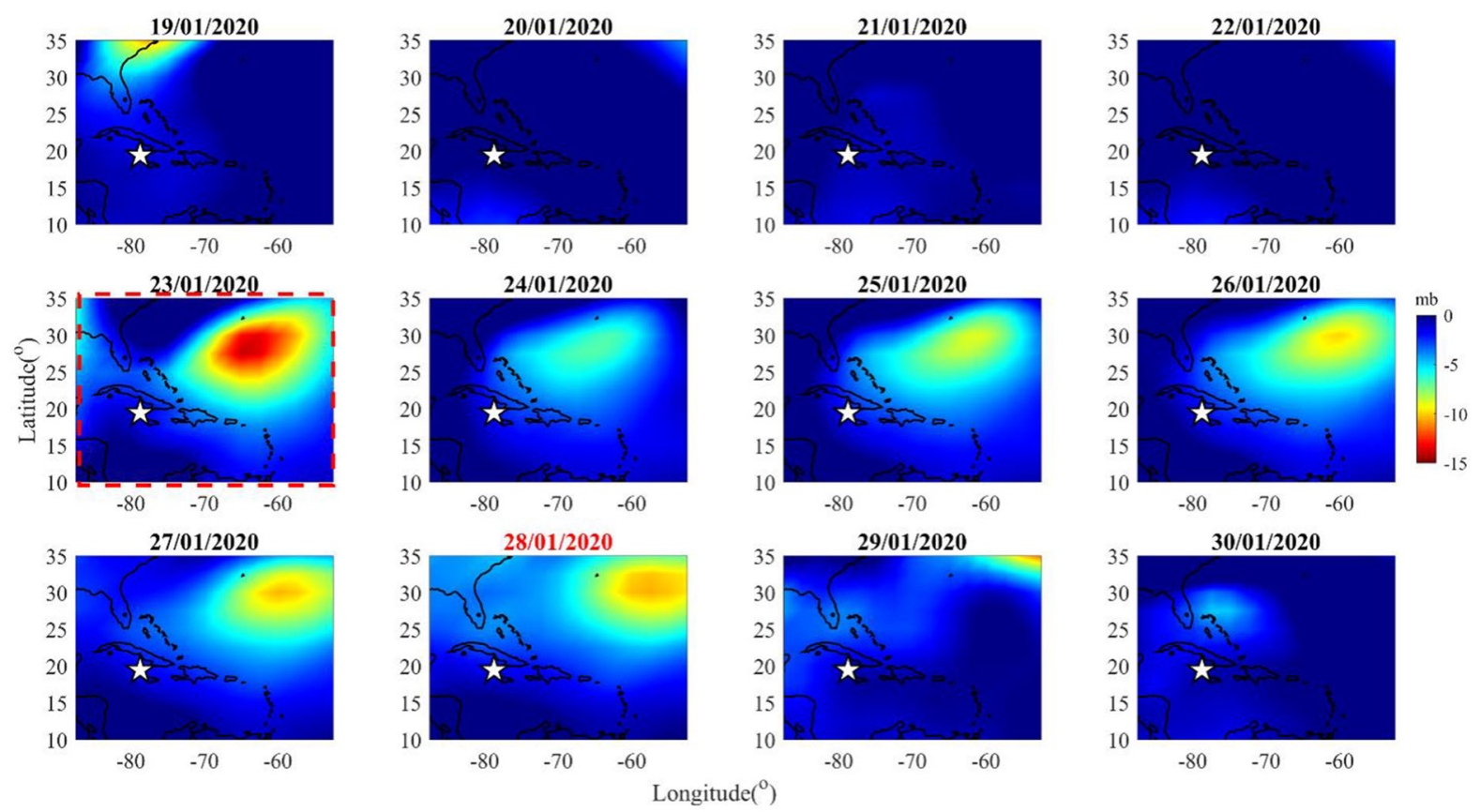

Figure 6

Air pressure anomaly maps from NOAA between January 19 and 30, 2020, at an altitude of $9 \mathrm{~km}$ above mean sea level. The epicenter of the Jamaican $7.7 \mathrm{EQ}$ is represented by a white star, and the anomalous day is denoted by a dashed-red square

one can observe that the ionospheric anomalies lasted for $6 \mathrm{~h}(\mathrm{LT}=13-19(-5 \mathrm{UT}))$. A maximum deviation of 4 TECU can be observed during these anomalous hours around the epicentral area. The demonstration of these anomalies conjectures their specificness concerning the region. Even though these fluctuations are local but the existence of geomagnetic storm catastrophe may mask these ionospheric anomalies. Figure 9 describes the geomagnetic conditions that indicate all quiet space weather on January 23, 2020. It can be observed that the Kp index remained less than 3, similarly, SYMH recorded greater than $-15 \mathrm{nT}$, and F10.7 remained less than 70 SFU on January 23, 2020. These results manifest that the ionospheric depletions observed over M 7.7 epicenter, are not contributed by geomagnetic activity.

Moreover, the GIMs demonstrate the observed TEC variations at the altitude of the fixed-height thin layer that is generally defined as $350-450 \mathrm{~km}$. Thus, to further explore the lower ionospheric variations, the vertical ionospheric profiles from F7/C2 were analyzed between LT $=13-19 \quad(-5$ UT). The selection of this specific period was subjected to the anomalous hours observed in the GIM-TEC maps. A considerable decrement of $\sim 10$ TECU from the corresponding median can be observed in ionospheric TEC profiles on January 23, 2020, between an altitude of $60-400 \mathrm{~km}$, as shown in Fig. 10. Additionally, the atmospheric profiles, including SAT and air pressure, have shown consistency with our spatial observation from NOAA-PSL, as they exhibited significant diminutions from their corresponding medians at different atmospheric altitudes, exploiting LAI interactions (Fig. 10). We further conducted a brief analysis to explore TEC behavior at the lower ionosphere by constructing the spatial F7/C2 TEC maps at seven $25 \mathrm{~km}$ altitude intervals from 75 to $225 \mathrm{~km}$, right above the epicenter. A co-located chained synchronous reduction was observed in TEC values, explicitly, over a small region above the epicenter between LT $=13-19$ ( -5 UT), as represented by Fig. 11. Between 75 and $125 \mathrm{~km}$, the TEC values are extremely reduced (less than 50 TECU), while between 150 and175 $\mathrm{km}$ the TEC values seemed to be diluted but remained significant 

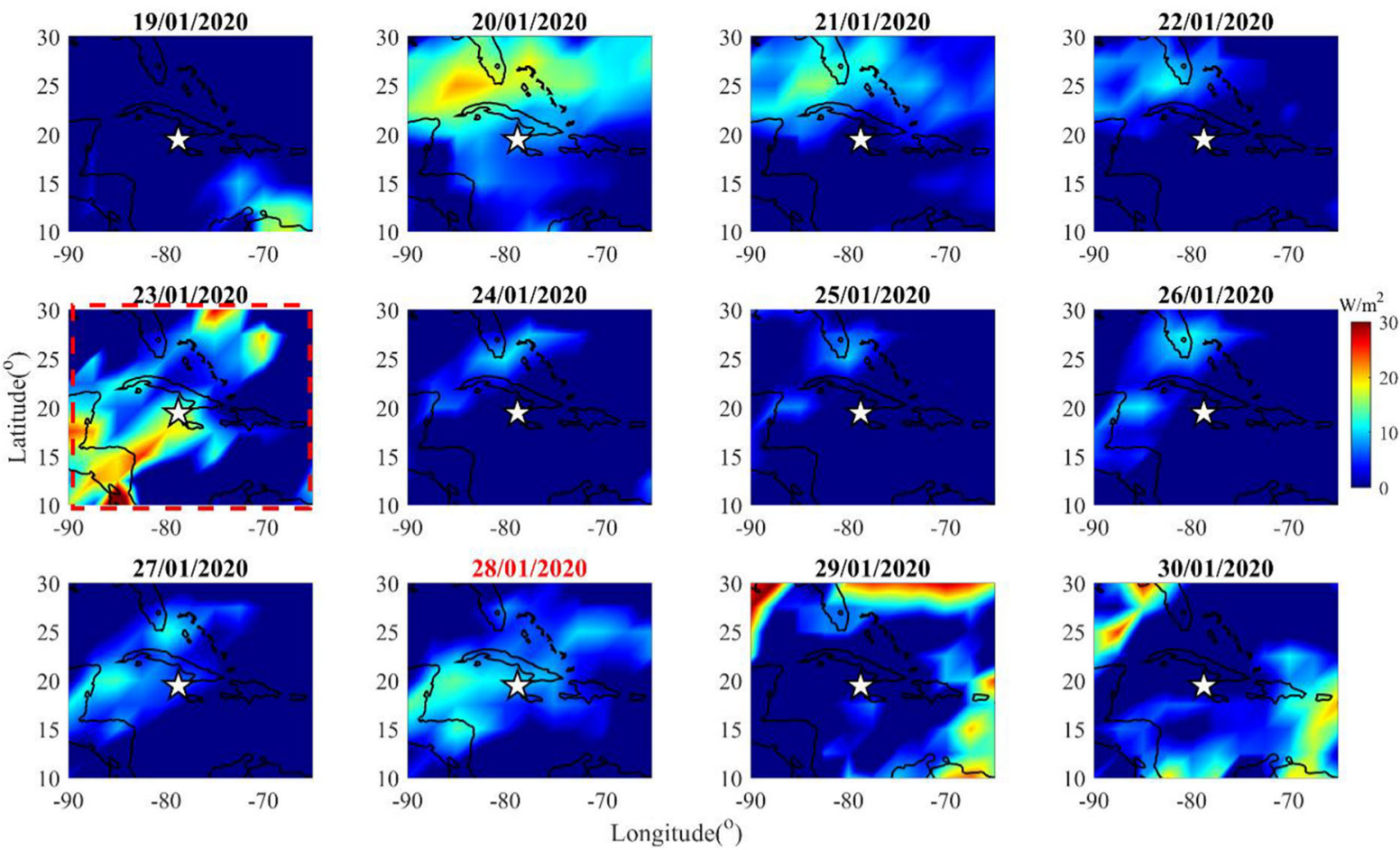

Figure 7

Spatial anomaly maps of OLR between January 20 and 28, 2020, at top of the atmosphere (altitude $=12 \mathrm{~km}($ above mean sea level)). The dashed-red rectangle shows the anomalous day and the white star represents the epicenter

compared to surroundings, whereas between 200 and $225 \mathrm{~km}$ the significance of TEC reductions again increased. It can be observed that the existence of these TEC anomalies is extremely local and ornately persuaded by the seismogenic electric field generated from air ionization produced from the increased radon activity at the PBL.

After meticulous analysis, these results incite a LAIC phenomenon before M 7.7 that could be considered as potential short-term precursors. In Fig. 11, all the results have been summarized into a single framework that explicates the formation of seismically induced anomalies from the surface to the ionosphere, at different altitude levels, divulging the LAIC. Our results confirm the LAIC phenomenon proposed by Pulinets et al. (2015) and provide deep insight into earth-atmosphere processes leading to ionospheric changes, where the time and space synchronization of all parameters on 23 January demonstrates the system proximity to the critical point.

\section{Discussion}

With respect to the perception of the EQ preparation area (Dobrovolsky et al., 1979) for M 7.7 Jamaica EQ, which has the spread over $0-36^{\circ} \mathrm{N}$ in latitude and $58-98^{\circ} \mathrm{W}$ in longitudes, the whole Caribbean sea, and associated islands have experienced the structural deformation, so the radon enhancements might have experienced throughout the region. Although due to data limitations, the direct radon measurements are not presented in this study. Nevertheless, the ACP can serve as a proxy of radon activity (Pulinets et al., 2015). Its temporal evolution for January 2020 in the epicenter of the Jamaica EQ demonstrates the sharp increase within the time interval of 22-25 January that can be interpreted as increased radon activity. It is quite natural that our results show strong evidence of air ionization production due to increased radon emanations and atmospheric coupling that further induced ionospheric variabilities. The enhanced radon excretions 

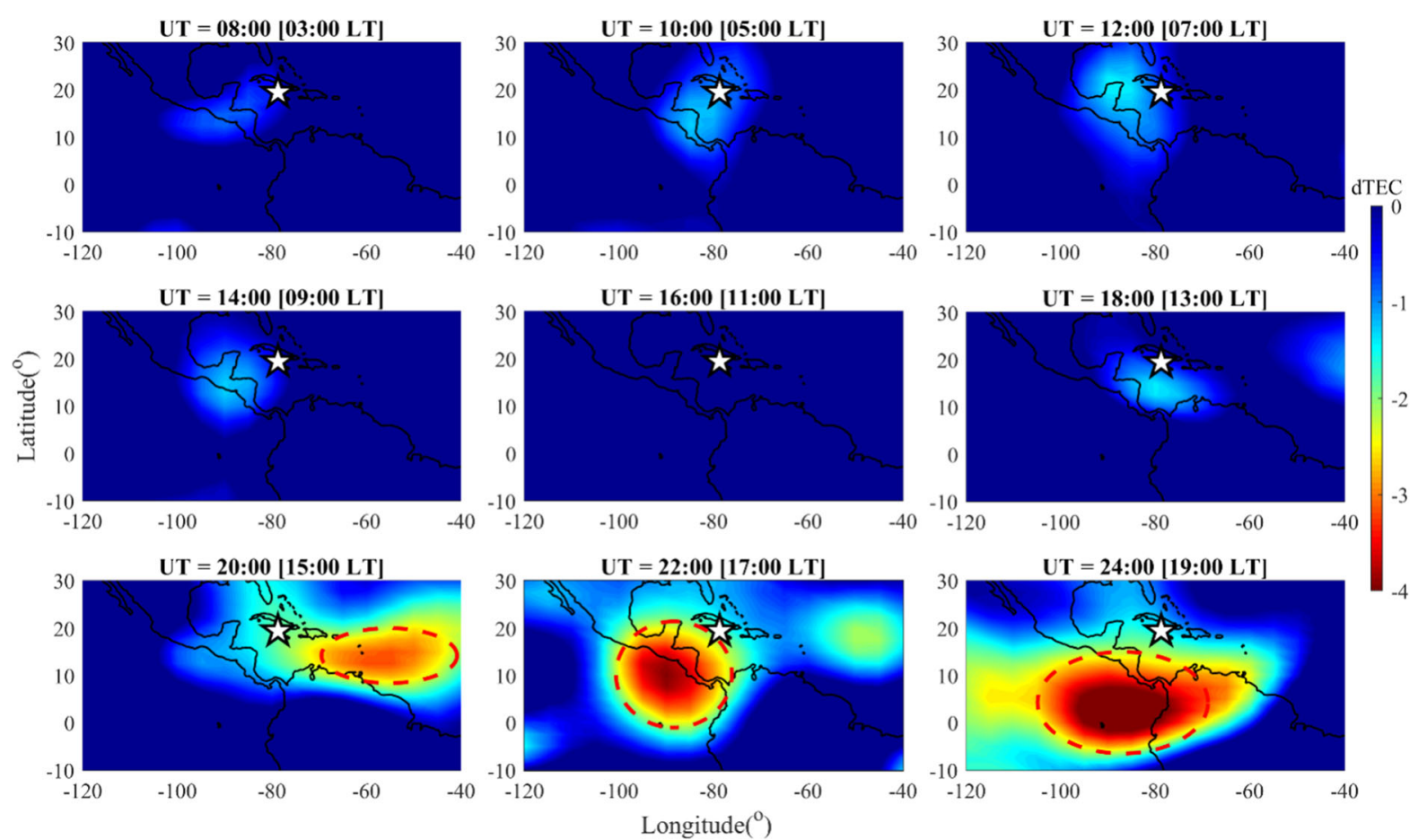

Figure 8

The ionospheric GIM-TEC maps from the International GNSS Service (IGS) on January 23, 2020 (5 days before EQ), in the form of difference TEC (dTEC) that were obtained by subtracting the observed day values by the mean of the previous 30 -days. The white star represents the location of the M 7.7 tremor and the dashed-red circle denotes the location of the anomalies

serve as the condensation of water droplets and consequently, latent heat of vaporization produced. This condensation takes place due to a drop in relative humidity at any level (mid-troposphere) with an appropriate range.

In our analysis, we have found strong evidence of the air ionization production in the form of simultaneously increasing ACP and total column water vapor and decreasing relative humidity and air temperature over the epicenter of the Jamaica EQ that led to the production of OLR anomalies and a drop in the air pressure on January 23, 2020. Since these are the climatological parameters, therefore, we have analyzed the 5-years mean of these parameters between the years 2015-2019, where no significant seismicity was present, to ensure that the observed atmospheric anomalies are unique and not periodic. To make a confutation analysis, we have investigated the datasets of the SAT, relative humidity, and total column water vapor for the year 2019 in January (Figs. 2 and 3). From Fig. 2, we can see that the SAT time series for the year 2019 exhibit very normal behavior with respect to the 5-years mean and the corresponding UB/LB without showing any abnormality throughout the month. Similarly, the time series of the column water vapor for the year 2019 also demonstrates the usual posture without any abrupt enhancement compared to the UB and 5-years mean (Fig. 3a). Moreover, the 2019 year's temporal variations of relative humidity have exhibited normal distribution with respect to 5-year mean and LB except on January 31, 2019, where we can observe an abrupt decrease (Fig. 3b), but interestingly enough, we did not find any simultaneous variations neither in the form of increased water vapor nor in air temperature on this particular day (Figs. 2 and 3). It means that this decrease in the relative humidity might be a climatological effect that didn't affect the water vapor and air temperature. It is noteworthy that the variations in the air temperature and water vapor are the ultimate source of the condensation process, which strengthens our findings before the M 7.7 


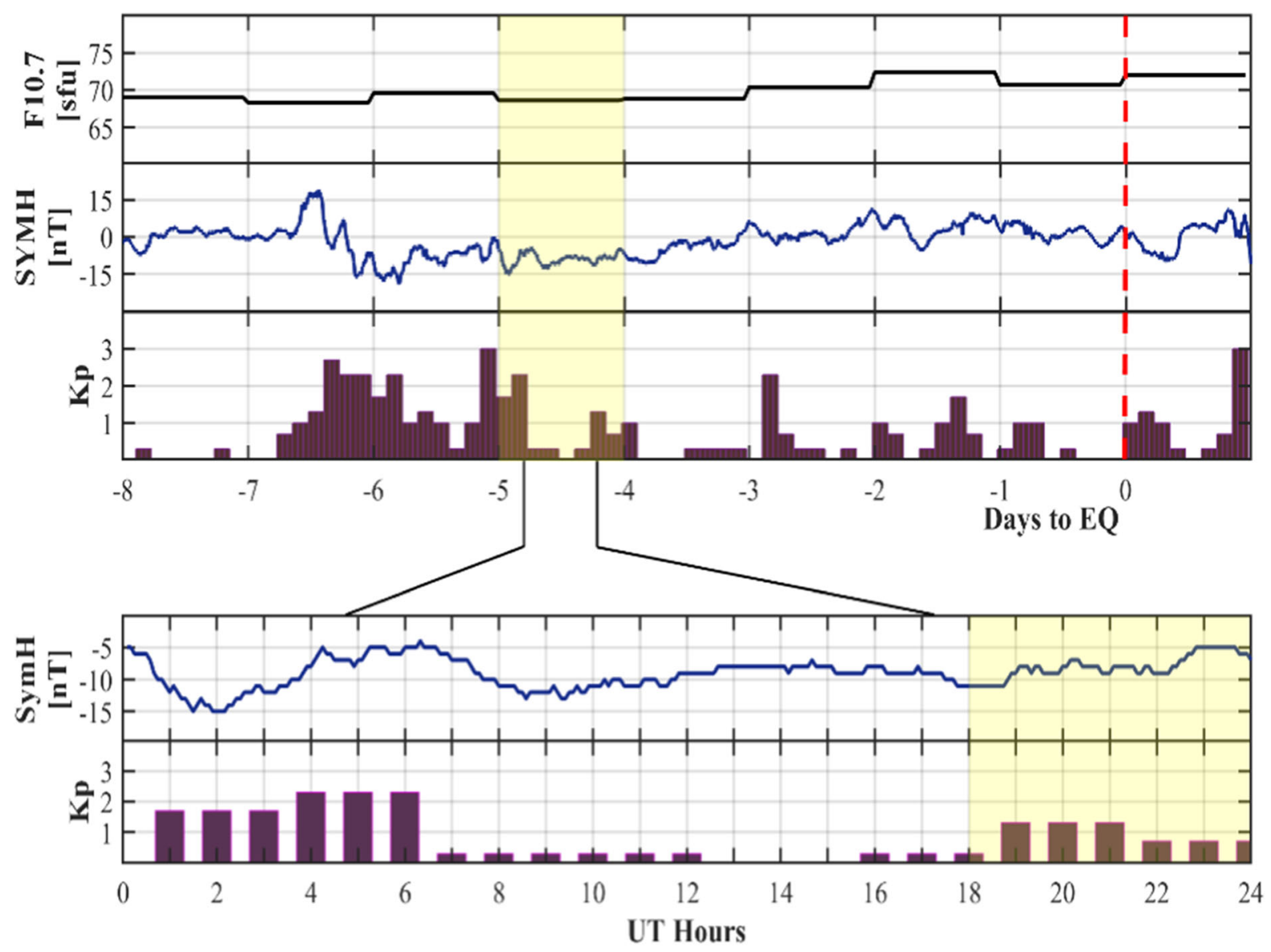

Figure 9

Solar and geomagnetic indices with a temporal resolution of 5 min: the top three panels hold solar index F10.7, SMYH (a high-resolution form of Dst index), and Kp index, between January 20 and 28, 2020. While the lower two panels carry the 24-h variations of SYMH and Kp indices for January 23, 2020, where the x-axis contains UT hours. The yellow highlighted area represents an anomalous period

Jamaica seismic event. This confutation analysis suggests that the simultaneous variations in relative humidity, SAT, and total column water vapor, observed on January 23, 2020, are peerlessly unique that demonstrates the production of air ionization over the seismic preparation zone.

According to Pulinets and Ouzounov (2018), a drop in relative humidity due to radon emissions, and increased column water vapor are mainly responsible for the condensation process, and as a consequence, latent heat releases. Furthermore, according to İnan et al. (2008), the rate of radon enhancements due to seismic activity may attain a value of $\sim 2000 \mathrm{~Bq} /$ $\mathrm{m}^{3}$. Whereas, the radon ion production rate is $\sim 6 \times$ $10^{8} \mathrm{~s}^{-1}$ and latent heat constant is approximately equal to $40.68 \times 10^{3} \mathrm{j} / \mathrm{mol}$. Hence, heat energy of about $16 \mathrm{~W} / \mathrm{m}^{2}$ should be released for given radon measurement and associated formation of ions having a size of $1 \mu \mathrm{m}$ (Pulinets et al., 2015), which agrees with OLR measurements of $20 \mathrm{~W} / \mathrm{m}^{2}$ registered by (Ouzounov et al., 2007). Similarly, the OLR measurements recorded in our study exceeds $30 \mathrm{~W} / \mathrm{m}^{2}$ (Fig. 7), which also provides strong evidence of seismically induced radon before M 7.7 EQ. Furthermore, air ionization at PBL is largely responsible for changes in the Global Electric Circuit (GEC), which is further responsible for atmospheric-ionospheric coupling. The pleonastic conception of GEC is discussed by Pulinets and Davidenko (2014) and Pulinets et al. (2015). They explained that the main 
(a)

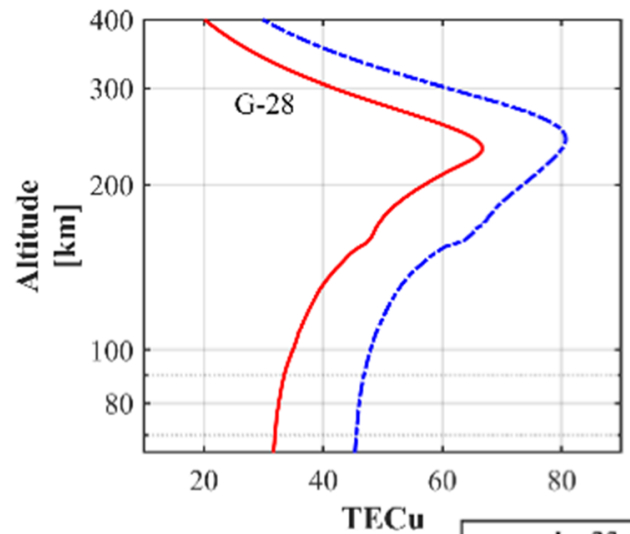

(b)

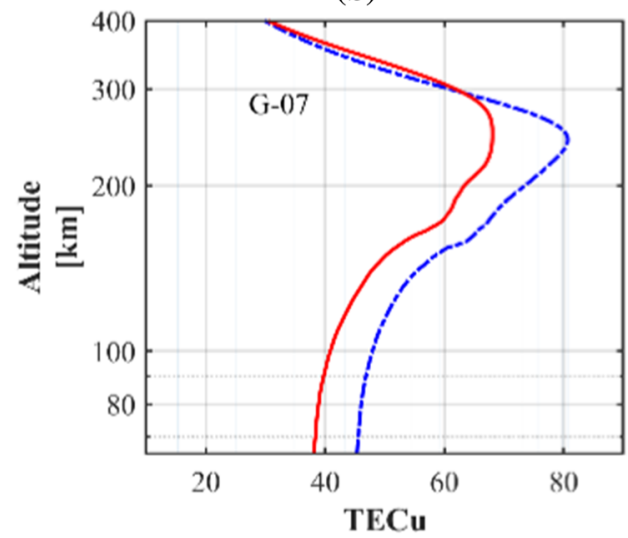

(c)

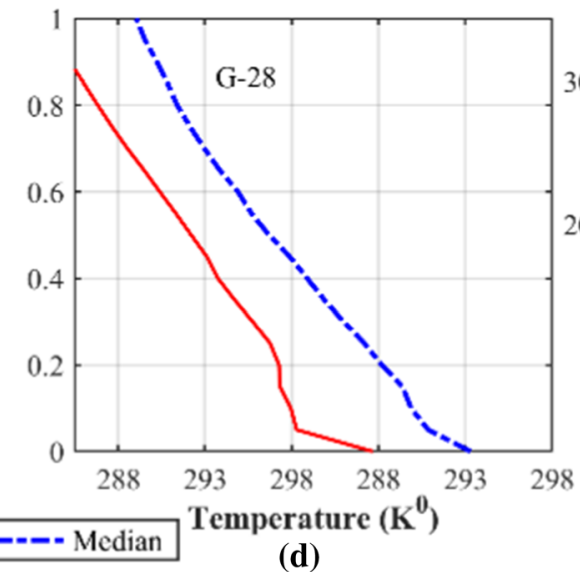

G-28 Ground Tracks
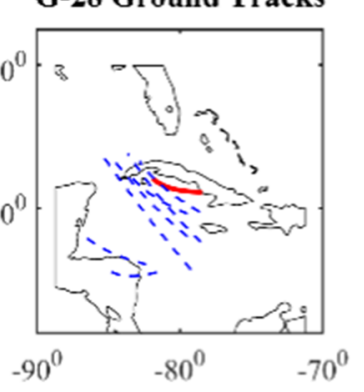

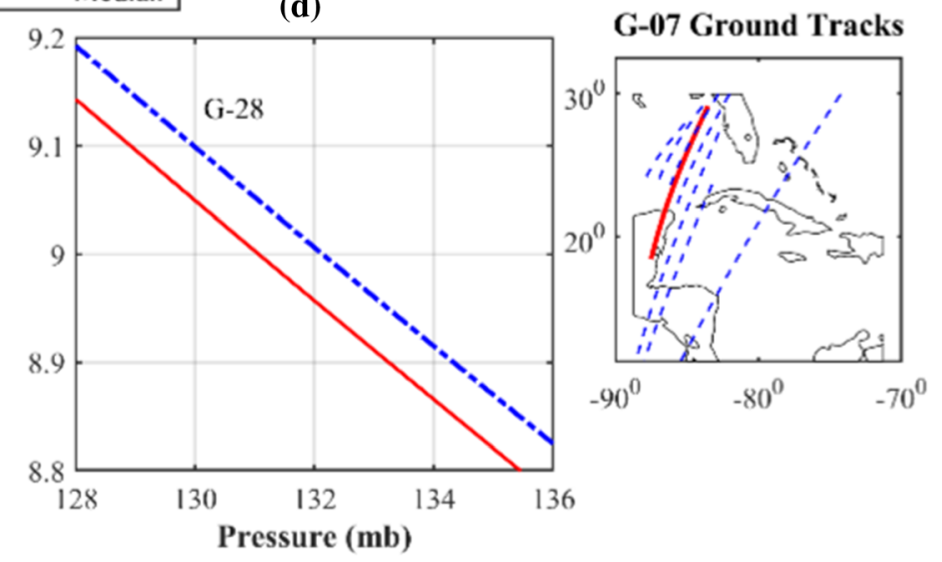

Figure 10

Ionospheric and atmospheric parameters extracted from F7/C2 satellites. a Ionospheric TEC from GNSS G-28 at LT = 14:58. b Ionospheric TEC from GNSS G-07 at LT $=17$. c Air temperature at surface. d Air Pressure at $9 \mathrm{~km}$. The solid-red line represents observed data on January 23, 2020, whereas the dashed-dotted-blue line represents the median values calculated from the median of 10 days before the observed day. The other geographical plots denote the ground track followed by these two satellites, around the epicenter, where the solid red line represents January 23, 2020, and the other blue lines represent the ground tracks of median days. The analysis level of TEC profiles was truncated to an altitude between 60 and $400 \mathrm{~km}$

forces that drive the GEC are thunderstorms and large radioactive structures (such as radon ionization) that produce vertical electric current over the planetary boundary. The PBL is largely dependent on variable plate boundary resistance, once the resistance is changed, the current flow between the atmosphere and ionosphere will also change. Moreover, the variations in the ionosphere are largely dependent on PBL, a sharp increase in radon measurements may lead to ionospheric depletions causing an increase in atmospheric boundary conductivity. In our case, we also recorded ionospheric depletions of about 4 TECU in GIM-TEC (Fig. 8) that demonstrate radon enhancements and consequent LAIC phenomenon. Figure 11 portrays an overview of the LAIC phenomenon observed before large Jamaica EQ, where a chained synchronous anomaly pattern can be observed. Similar findings were registered by Giuliani et al. (2009), where a radon anomaly followed by anomalies in SAT and OLR, and further in the ionospheric TEC was detected.

The exhibition of concomitant anomalies from the surface to the ionosphere indicates an abrupt increase in radon emissions lead by tectonic activity that could be considered as potential EQ precursors before $\mathrm{M}$ 7.7 Jamaica EQ. 


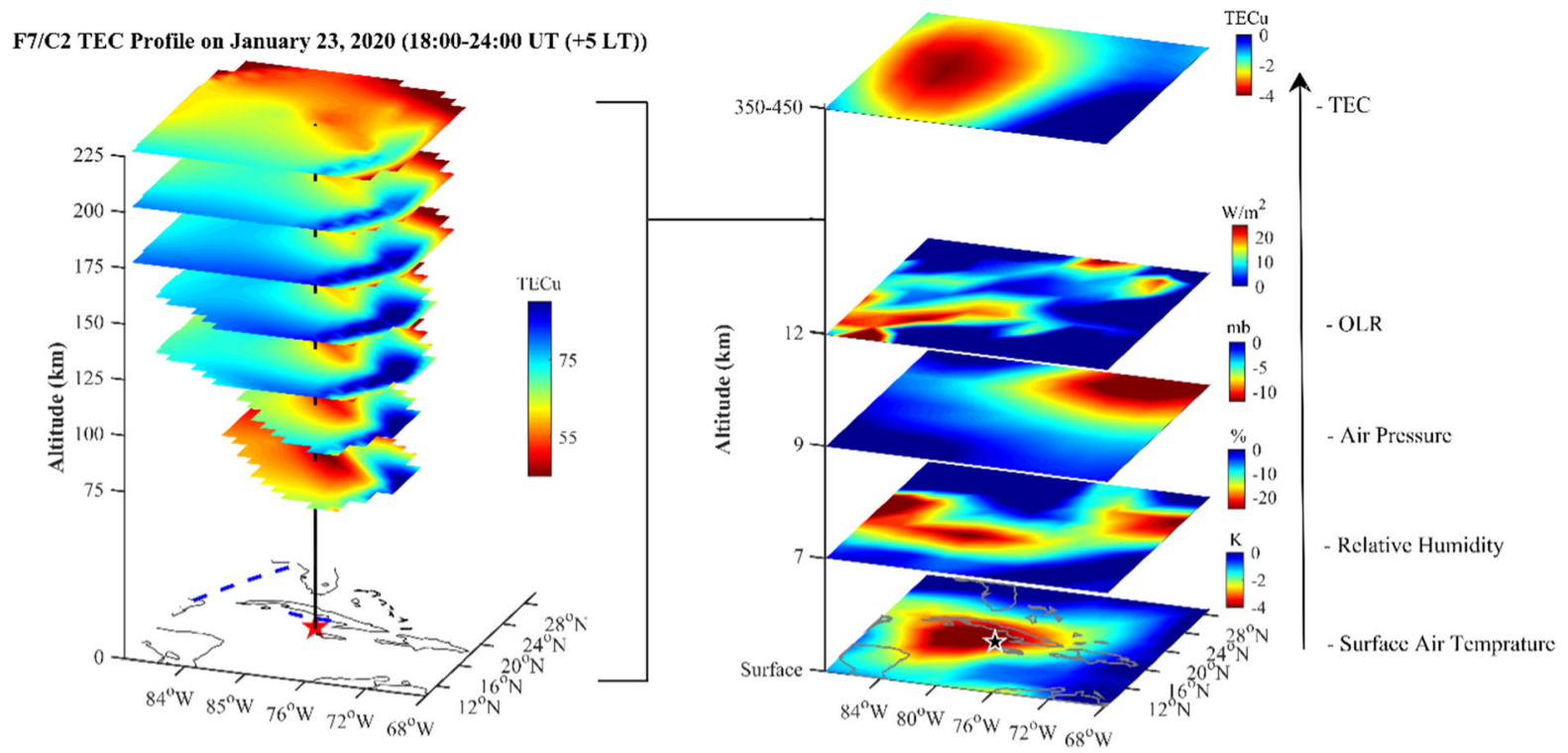

Figure 11

(Left) The ionospheric TEC maps constructed from F7/C2 satellites data with a spatial resolution of $1^{\circ}$, between an altitude of $75-225 \mathrm{~km}$. (Right) Exhibition and validation of the LAIC phenomenon (from the surface to the ionosphere)

\section{Conclusion}

This paper presents the anomalous conditions observed before Jamaica EQ of January 28, 2020, in pursuit of a possible precursory phenomenon. We observed a reduction of $25 \%$ in relative humidity, 14 $\mathrm{mb}$ in air pressure, and $4 \mathrm{~K}$ in the SAT, which provides evidence of increased radon emanations about five days before the EQ. The simultaneous variations in the form of a drop in relative humidity, SAT, and increased total column water vapor, as well as dropping air pressure and increasing OLR, indicate the production of air ionization through the condensation of water vapor in the atmosphere. On the other hand, our confutation analysis, based on the datasets of the previous 5 years in the same month and region, confirmed that the observed variations are categorically unique and not periodic in the absence of significant seismicity periods. Moreover, we observed an ionospheric anomaly in the form of GIM-TEC and F7/C2 TEC profiles as a result of the air ionization production over the atmospheric boundary layer that exhibits a LAIC phenomenon. An overview of the LAIC phenomenon and a summary of these results are presented in Fig. 11. Even though our results evidenced the occurrence of seismic ionospheric precursors, but still we suggest that due to the diverse nature of the ionospheric environment, as it is very vulnerable to other sources such as traveling ionospheric disturbances and solar activity, etc., it will be very arduous and complicated to find an EQ precursor in the ionosphere during the presence of high geomagnetic conditions and solar activities.

The combined approach used in this study (from the ground to the ionosphere) has never been used previously by any researcher. We recommend more precursory analysis with a similar approach to further explore the LAIC phenomenon. We believe that our multi-precursory analysis at different altitude levels is another conferment to comprehend the LAIC phenomenon and future EQ forecasting.

\section{Acknowledgements}

The authors are extremely thankful to Editor-in-Chief Alexander Rabinovich and two anonymous referees for their valuable comments and suggestions in improving the manuscript quality. We are indebted 
to the NOAA-PSL community for providing the atmospheric datasets, NASA's Global Modelling and Assimilation Office for providing the datasets of total column water vapor, relative humidity, and SAT, the IGS network for providing the GIM-TEC maps, and Taiwan's National Space Organization (NSPO) / University Corporation for Atmospheric Research (UCAR) of the U.S. for F7/C2 datasets. We are also obliged to the United States Geological Survey (USGS) for providing information about the EQ and OMNIWEB NASA for providing the space-weather indices.

\section{Declarations}

Conflict of Interest None of these persons have any conflict of interest, financial or otherwise.

Publisher's Note Springer Nature remains neutral with regard to jurisdictional claims in published maps and institutional affiliations.

\section{REFERENCES}

Adil, M. A., Abbas, A., Ehsan, M., Shah, M., Naqvi, N. A., \& Alie, A. (2021a). Investigation of ionospheric and atmospheric anomalies associated with three $\mathrm{Mw}>6.5 \mathrm{EQs}$ in New Zealand. Journal of Geodynamics, 145, 101841. https://doi.org/10.1016/j. jog.2021.101841

Adil, M. A., Şentürk, E., Shah, M., Naqvi, N. A., Saqib, M., \& Abbasi, A. R. (2021b). Atmospheric and ionospheric disturbances associated with the $M>6$ earthquakes in the East Asian sector: A case study of two consecutive earthquakes in Taiwan. Journal of Asian Earth Sciences, 220, 104918. https://doi.org/10. 1016/j.jseaes.2021.104918

Afraimovich, E. L., \& Astafyeva, E. I. (2008). TEC anomaliesLocal TEC changes prior to earthquakes or TEC response to solar and geomagnetic activity changes? Earth, Planets and Space, 60(9), 961-966. https://doi.org/10.1186/BF03352851

Blackett, M., Wooster, M. J., \& Malamud, B. D. (2011). Exploring land surface temperature earthquake precursors: A focus on the Gujarat (India) earthquake of 2001. Geophysical Research Letters, 38(15), L15303. https://doi.org/10.1029/2011GL048282

Boyarchuk, K. A., Karelin, A. V., \& Shirokov, R. V. (2006). The base model of kinetics of the ionized atmosphere. IPG VNII EM. in Russian.

Boyarchuk, K. A., Lomonosov, A. M., Pulinets, S. A., \& Hegai, V. V. (1998). Variability of the earth's atmospheric electric field and ion-aerosol kinetics in the Troposphere. Studia Geophysica Et Geodaetica, 42, 197-206. https://doi.org/10.1023/A: 1023313222390

Cervone, G., Maekawa, S., Singh, R. P., Hayakawa, M., Kafatos, M., \& Shvets, A. (2006). Surface latent heat flux and nighttime $\mathrm{LF}$ anomalies prior to the $\mathrm{M} \mathrm{w}=8.3$ Tokachi-Oki earthquake.
Natural Hazards and Earth System Sciences, 6, 109-114. https:// doi.org/10.5194/nhess-6-109-2006

De Santis, A., De Franceschi, G., Spogli, L., et al. (2015). Geospace perturbations induced by the Earth: The state of the art and future trends. Physics and Chemistry of the Earth, Parts A/b/c, 85, 17-33. https://doi.org/10.1016/j.pce.2015.05.004

De Santis, A., Marchetti, D., Pavón-Carrasco, F. J., et al. (2019). Precursory worldwide signatures of earthquake occurrences on Swarm satellite data. Scientific Reports, 9(1), 1-13. https://doi. org/10.1038/s41598-019-56599-1

Dobrovolsky, I. P., Zubkov, S. I., \& Miachkin, V. I. (1979). Estimation of the size of earthquake preparation zones. Pure and Applied Geophysics, 117(5), 1025-1044. https://doi.org/10.1007/ BF00876083

Dunajecka, M. A., \& Pulinets, S. A. (2005). Atmospheric and thermal anomalies observed around the time of strong earthquakes in Mexico. Atmósfera, 18(4), 235-247. https://www. revistascca.unam.mx/atm/index.php/atm/article/view/8549. Accessed 27 Dec 2020.

Freeshah, M., Zhang, X., Şentürk, E., et al. (2021). Analysis of atmospheric and ionospheric variations due to impacts of super typhoon Mangkhut (1822) in the Northwest Pacific Ocean. Remote Sensing., 13, 661. https://doi.org/10.3390/rs13040661

Freund, F. T., Kulahci, I. G., Cyr, G., et al. (2009). Air ionization at rock surfaces and pre-earthquake signals. Journal of Atmospheric and Solar-Terrestrial Physics, 71(17-18), 1824-1834. https:// doi.org/10.1016/j.jastp.2009.07.013

Geller, R. J. (1997). Earthquake prediction: A critical review. Geophysical Journal International, 131(3), 425-450. https://doi. org/10.1111/j.1365-246X.1997.tb06588.x

Giuliani, G. G., Giuliani, R., Totani, G., Eusani, G., \& Totani, F. (2009). Radon observations by gamma detectors "PM-4 and PM2" during the seismic period (January-April 2009) in L'Aquila Basin. AGUFM, U14A-03. https://ui.adsabs.harvard.edu/abs/ 2009AGUFM.U14A..03G. Accessed 18 Jan 2021.

Hauksson, E. (1981). Radon content of groundwater as an earthquake precursor: Evaluation of worldwide data and physical basis. Journal of Geophysical Research: Solid Earth, 86(B10), 9397-9410. https://doi.org/10.1029/JB086iB10p09397

Hernández-Pajares, M., Juan, J. M., Sanz, J., et al. (2009). The IGS VTEC maps: A reliable source of ionospheric information since 1998. Journal of Geodesy, 83(3-4), 263-275. https://doi.org/10. 1007/s00190-008-0266-1

Ho, S.-P., Zhou, X., Shao, X., et al. (2020). Initial assessment of the COSMIC-2/FORMOSAT-7 neutral atmosphere data quality in NESDIS/STAR using in situ and satellite data. Remote Sensing., 12(24), 4099. https://doi.org/10.3390/rs12244099

Hsiao, C. C., Liu, J. Y., Oyama, K. I., Yen, N. L., Wang, Y. H., \& Miau, J. J. (2009). Ionospheric electron density anomaly prior to the December 26, 2006 M7.0 Pingtung earthquake doublet observed by FORMOSAT-3/COSMIC. Physics and Chemistry of the Earth, Parts A/b/c, 34(6-7), 474-478. https://doi.org/10. 1016/j.pce.2008.06.058

İnan, S., Akgül, T., Seyis, C., et al. (2008). Geochemical monitoring in the Marmara region (NW Turkey): A search for precursors of seismic activity. Journal of Geophysical Research: Solid Earth. https://doi.org/10.1029/2007JB005206

Kamogawa, M. (2006). Preseismic lithosphere-atmosphere-ionosphere coupling. Eos, Transactions American Geophysical Union, 87(40), 417-424. https://doi.org/10.1029/2006EO400002 
Keilis-Borok, V. I., \& Soloviev, A. A. (Eds.). (2003). Fundamentals of earthquake prediction: four paradigms. In: Nonlinear dynamics of the lithosphere and earthquake prediction (pp. 1-36). Springer (ISBN 978-3-662-05298-3).

King, C. Y. (1981). Do radon anomalies predict earthquakes? Nature, 293(5830), 262-262. https://doi.org/10.1038/293262a0

Kuo, C. L., Lee, L. C., \& Huba, J. D. (2014). An improved coupling model for the lithosphere-atmosphere-ionosphere system. Journal of Geophysical Research: Space Physics, 119(4), 3189-3205. https://doi.org/10.1002/2013JA019392

Liu, J. Y., Chen, C. H., Chen, Y. I., Yang, W. H., Oyama, K. I., \& Kuo, K. W. (2010). A statistical study of ionospheric earthquake precursors monitored by using equatorial ionization anomaly of GPS TEC in Taiwan during 2001-2007. Journal of Asian Earth Sciences, 39(1-2), 76-80. https://doi.org/10.1016/j.jseaes.2010. 02.012

Mansouri Daneshvar, M. R., \& Freund, F. T. (2017). Remote sensing of atmospheric and ionospheric signals prior to the Mw 8.3 Illapel earthquake, Chile 2015. Pure and Applied Geophysics, 174, 11-45. https://doi.org/10.1007/s00024-016-1366-0

Mansouri Daneshvar, M. R., Tavousi, T., \& Khosravi, M. (2014). Synoptic detection of the short-term atmospheric precursors prior to a major earthquake in the Middle East, North Saravan M 7.8 earthquake, SE Iran. Air Quality, Atmosphere \& Health, 7(1), 29-39. https://doi.org/10.1007/s11869-013-0214-y

Marchetti, D., De Santis, A., D'Arcangelo, S., et al. (2020). Magnetic field and electron density anomalies from Swarm satellites preceding the major earthquakes of the 2016-2017 Amatrice-Norcia (Central Italy) seismic sequence. Pure and Applied Geophysics, 177(1), 305-319. https://doi.org/10.1007/ s00024-019-02138-y

Masci, F., \& Thomas, J. N. (2014). Comment on "Temporal and spatial precursors in ionospheric total electron content of the 16 October $1999 \mathrm{Mw} 7.1$ Hector Mine earthquake" by Su et al. 2013. Journal of Geophysical Research: Space Physics, 119(8), 6994-6997. https://doi.org/10.1002/2014JA019896

Mollo, S., Tuccimei, P., Heap, M. J., et al. (2011). Increase in radon emission due to rock failure: An experimental study. Geophysical Research Letters. https://doi.org/10.1029/2011GL047962

Ouzounov, D., Liu, D., Chunli, K., Cervone, G., Kafatos, M., \& Taylor, P. (2007). Outgoing long wave radiation variability from IR satellite data prior to major earthquakes. Tectonophysics, 431(1-4), 211-220. https://doi.org/10.1016/j.tecto.2006.05.042

Ouzounov, D., Pulinets, S., Hattori, K., \& Taylor, P. (2018). Preearthquake processes: A multidisciplinary approach to earthquake prediction studies (Vol. 234). Wiley. https://doi.org/10. 1002/9781119156949

Ouzounov, D., Pulinets, S., Romanov, A., et al. (2011). Atmosphere-ionosphere response to the M9 Tohoku earthquake reviled by joined satellite and ground Observations. Earthquake Science, 24(6), 557-564. https://doi.org/10.1007/s11589-011-0817-z

Oyama, K. I., Kakinami, Y., Liu, J. Y., Abdu, M. A., \& Cheng, C. Z. (2011). Latitudinal distribution of anomalous ion density as a precursor of a large earthquake. Journal of Geophysical Research: Space Physics. https://doi.org/10.1029/2010JA015948

Planinić, J., Radolić, V., \& Lazanin, Ž. (2001). Temporal variations of radon in soil related to earthquakes. Applied Radiation and Isotopes, 55(2), 267-272. https://doi.org/10.1016/S09698043(00)00387-0

Pulinets, S., \& Davidenko, D. (2014). Ionospheric precursors of earthquakes and global electric circuit. Advances in Space
Research, 53(5), 709-723. https://doi.org/10.1016/j.asr.2013.12. 035

Pulinets, S. A., \& Ouzounov, D. (2018). The Possibility of earthquake forecasting: Learning from nature (p. 167). IOP Publishing. https://doi.org/10.1088/978-0-7503-1248-6

Pulinets, S. A., Kotsarenko, A. N., Ciraolo, L., \& Pulinets, I. A. (2007). Special case of ionospheric day-to-day variability associated with earthquake preparation. Advances in Space Research, 39(5), 970-977. https://doi.org/10.1016/j.asr.2006.04.032

Pulinets, S. A., Ouzounov, D. P., Karelin, A. V., \& Davidenko, D. V. (2015). Physical bases of the generation of short-term earthquake precursors: A complex model of ionization-induced geophysical processes in the lithosphere-atmosphere-ionospheremagnetosphere system. Geomagnetism and Aeronomy, 55(4), 521-538. https://doi.org/10.1134/S0016793215040131

Richon, P., Sabroux, J. C., Halbwachs, M., et al. (2003). Radon anomaly in the soil of Taal volcano, the Philippines: a likely precursor of the M 7.1 Mindoro earthquake (1994). Geophysical Research Letters, 30, 9. https://doi.org/10.1029/2003GL016902

Schreiner, W. S., Weiss, J. P., Anthes, R. A., et al. (2020). COSMIC-2 radio occultation constellation: First results. Geophysical Research Letters. https://doi.org/10.1029/2019GL086841

Şentürk, E., Livaoğlu, H., \& Çepni, M. S. (2019). A comprehensive analysis of ionospheric anomalies before the Mw 7.1 Van earthquake on 23 October 2011. The Journal of Navigation, 72(3), 702-720. https://doi.org/10.1017/S0373463318000826

Su, Y. C., Liu, J. Y., Chen, S. P., Tsai, H. F., \& Chen, M. Q. (2013). Temporal and spatial precursors in ionospheric total electron content of the 16 October 1999 Mw7.1 Hector Mine earthquake. Journal of Geophysical Research: Space Physics, 118(10), 6511-6517. https://doi.org/10.1002/jgra.50586

Syndergaard, S., Kursinski, E. R., Herman, B. M., Lane, E. M., \& Flittner, D. E. (2005). A refractive index mapping operator for assimilation of occultation data. Monthly Weather Review, 133(9), 2650-2668. https://doi.org/10.1175/MWR3001.1

Thomas, J. N., Love, J. J., Komjathy, A., Verkhoglyadova, O. P., Butala, M., \& Rivera, N. (2012). On the reported ionospheric precursor of the 1999 Hector Mine, California earthquake. Geophysical Research Letters. https://doi.org/10.1029/ 2012GL051022

Toker, M. (2021). Symptomatic discretization of small earthquake clusters reveals seismic coupling to 2017 Bodrum earthquake (Mw 6.6) in the Gulf of Gökova (SW corner of Turkey): Viscouscompliant seismogenesis over back-arc setting. Journal of African Earth Sciences, 177, 104156. https://doi.org/10.1016/j. jafrearsci.2021.104156

Tuccimei, P., Mollo, S., Vinciguerra, S., Castelluccio, M., \& Soligo, M. (2010). Radon and thoron emission from lithophysaerich tuff under increasing deformation: An experimental study. Geophysical Research Letters. https://doi.org/10.1029/ 2009GL042134

U.S. Geological Survey (2020). Earthquake Lists, Maps, and Statistics. https://www.usgs.gov/natural-hazards/earthquakehazards/lists-maps-and-statistics. Accessed 9 Feb 2021.

Varotsos, C. A., Efstathiou, M. N., \& Cracknell, A. P. (2017). On the association of aerosol optical depth and total ozone fluctuations with recent earthquakes in Greece. Acta Geophysica, 65, 659-665. https://doi.org/10.1007/s11600-017-0051-8

Wielgosz, P., Milanowska, B., Krypiak-Gregorczyk, A., \& Jarmołowski, W. (2021). Validation of GNSS-derived global ionosphere maps for different solar activity levels: Case studies 
for years 2014 and 2018. GPS Solutions, 25(3), 1-15. https://doi. org/10.1007/s10291-021-01142-x

Wilding, R. J., \& Harrison, R. G. (2005). Aerosol modulation of small ion growth in coastal air. Atmospheric Environment, 39(32), 5876-5883. https://doi.org/10.1016/j.atmosenv.2005.06. 020

Woith, H. (2015). Radon earthquake precursor: A short review. The European Physical Journal Special Topics, 224(4), 611-627. https://doi.org/10.1140/epjst/e2015-02395-9

Xiong, P., Shen, X., Bi, Y., et al. (2010). Study of outgoing longwave radiation anomalies associated with Haiti earthquake. Natural Hazards and Earth System Sciences, 10, 2169-2178. https://doi.org/10.5194/nhess-10-2169-2010

Yuan, Y., \& Ou, J. (2001). Auto-covariance estimation of variable samples (ACEVS) and its application for monitoring random ionospheric disturbances using GPS. Journal of Geodesy, 75(7-8), 438-447. https://doi.org/10.1007/s001900100197

Yuan, Y., \& Ou, J. (2002). Differential areas for differential stations (DADS): A new method of establishing grid ionospheric model. Chinese Science Bulletin, 47(12), 1033-1036. https://doi. org/10.1007/BF02907577

Yan, X., Sun, Y., Yu, T., et al. (2018). Stratosphere perturbed by the 2011 Mw9.0 Tohoku earthquake. Geophysical Research Letters, 45(19), 10-050. https://doi.org/10.1029/2018GL079046

Zhou, Y., Yang, J., Zhu, F., Su, F., Hu, L., \& Zhai, W. (2017). Ionospheric disturbances associated with the 2015 M7.8 Nepal earthquake. Geodesy and Geodynamics, 8(4), 221-228. https:// doi.org/10.1016/j.geog.2017.04.004

(Received March 7, 2021, revised September 7, 2021, accepted September 9, 2021) 


\section{Terms and Conditions}

Springer Nature journal content, brought to you courtesy of Springer Nature Customer Service Center GmbH ("Springer Nature"). Springer Nature supports a reasonable amount of sharing of research papers by authors, subscribers and authorised users ("Users"), for small-scale personal, non-commercial use provided that all copyright, trade and service marks and other proprietary notices are maintained. By accessing, sharing, receiving or otherwise using the Springer Nature journal content you agree to these terms of use ("Terms"). For these purposes, Springer Nature considers academic use (by researchers and students) to be non-commercial.

These Terms are supplementary and will apply in addition to any applicable website terms and conditions, a relevant site licence or a personal subscription. These Terms will prevail over any conflict or ambiguity with regards to the relevant terms, a site licence or a personal subscription (to the extent of the conflict or ambiguity only). For Creative Commons-licensed articles, the terms of the Creative Commons license used will apply.

We collect and use personal data to provide access to the Springer Nature journal content. We may also use these personal data internally within ResearchGate and Springer Nature and as agreed share it, in an anonymised way, for purposes of tracking, analysis and reporting. We will not otherwise disclose your personal data outside the ResearchGate or the Springer Nature group of companies unless we have your permission as detailed in the Privacy Policy.

While Users may use the Springer Nature journal content for small scale, personal non-commercial use, it is important to note that Users may not:

1. use such content for the purpose of providing other users with access on a regular or large scale basis or as a means to circumvent access control;

2. use such content where to do so would be considered a criminal or statutory offence in any jurisdiction, or gives rise to civil liability, or is otherwise unlawful;

3. falsely or misleadingly imply or suggest endorsement, approval, sponsorship, or association unless explicitly agreed to by Springer Nature in writing;

4. use bots or other automated methods to access the content or redirect messages

5. override any security feature or exclusionary protocol; or

6. share the content in order to create substitute for Springer Nature products or services or a systematic database of Springer

Nature journal content.

In line with the restriction against commercial use, Springer Nature does not permit the creation of a product or service that creates revenue, royalties, rent or income from our content or its inclusion as part of a paid for service or for other commercial gain. Springer Nature journal content cannot be used for inter-library loans and librarians may not upload Springer Nature journal content on a large scale into their, or any other, institutional repository.

These terms of use are reviewed regularly and may be amended at any time. Springer Nature is not obligated to publish any information or content on this website and may remove it or features or functionality at our sole discretion, at any time with or without notice. Springer Nature may revoke this licence to you at any time and remove access to any copies of the Springer Nature journal content which have been saved.

To the fullest extent permitted by law, Springer Nature makes no warranties, representations or guarantees to Users, either express or implied with respect to the Springer nature journal content and all parties disclaim and waive any implied warranties or warranties imposed by law, including merchantability or fitness for any particular purpose.

Please note that these rights do not automatically extend to content, data or other material published by Springer Nature that may be licensed from third parties.

If you would like to use or distribute our Springer Nature journal content to a wider audience or on a regular basis or in any other manner not expressly permitted by these Terms, please contact Springer Nature at

onlineservice@springernature.com 